\title{
Revisão narrativa sobre práticas de gestão ambiental nas instituições públicas de ensino superior brasileiras
}

\author{
RESUMO
}

Igor Laguna Vieira igor_laguna@hotmail.com Doutorando do Programa de Pós-Graduação em Engenharia Ambiental da Universidade do Estado do Rio de Janeiro (UERJ)

Elmo Rodrigues da Silva elmorodrigues@yahoo.com.br Professor do Programa de PósGraduação em Engenharia Ambiental da Universidade do Estado do Rio de Janeiro (UERJ)
Dada a importância do setor público para a questão ambiental no Brasil, em particular das Instituições de Ensino Superior (IES), propôs-se identificar e analisar práticas de gestão ambiental presentes em IES públicas brasileiras, tendo como base na técnica de revisão narrativa. Constatou-se, em algumas dessas instituições, a existência de práticas que visam melhorar sua relação com o meio ambiente. Foram observadas ainda propostas para ampliar a gestão ambiental nas IES. A crescente adesão à Agenda Ambiental na Administração Pública (A3P) por órgãos públicos, especialmente pelas IES, bem como as práticas de gestão ambiental identificadas, evidenciaram que as discussões e ações dirigidas para o desenvolvimento sustentável vêm aumentando seu espaço na sociedade brasileira. A implantação de uma adequada gestão ambiental mostrou-se fundamental na busca pela Responsabilidade Socioambiental das IES públicas, estimulando a legitimidade das ações nessas instituições, no contexto considerado.

PALAVRAS-CHAVE: Gestão Ambiental. Desenvolvimento Sustentável. Instituições de Ensino Superior. Agenda Ambiental na Administração Pública. A3P. 


\section{INTRODUÇÃO}

O termo sustentabilidade, como usualmente empregado, foi proposto no Relatório Brundtland, publicado em 1987, a despeito das questões ambientais terem sido muito discutidas ao longo dos anos que se seguiram, após a Conferência de Estocolmo (VAN BELLEN, 2004). Os cenários previam que o planeta caminhava para uma intensa degradação ambiental, com excessiva exploração dos recursos naturais, em conjunto com o aumento da pobreza e da população mundial (SERRA; MORAES, 2006). Mesmo após longas discussões, a conjugação dos interesses dos sistemas sociais com a conservação dos sistemas ambientais ainda se mostram como complexos desafios (KAHLAU et al., 2014).

Durante muito tempo, apenas a eficiência produtiva preocupava as organizações. Porém, num curto prazo de tempo essa ideia se mostrou um equívoco, devido à diversificação e à escala crescente dos processos produtivos, que elevou o consumo de recursos naturais (matérias-primas e insumos) e a quantidade de poluentes gerados e lançados no ambiente natural. Além disso, a fabricação de substâncias sintéticas perigosas contribuiu para a degradação ambiental. Houve então a necessidade de adaptação, especialmente para o cumprimento da legislação ambiental. Na ocasião, práticas de controle de "fim de tubo" foram adotadas, com o objetivo de adequar a emissão de efluentes líquidos e atmosféricos aos padrões ambientais que estavam sendo estabelecidos. Mais tarde, ações voltadas à gestão ambiental, de forma geral, evidenciaram as vantagens econômicas que tais práticas possibilitaram. O maior objetivo da gestão ambiental é a busca contínua de melhoria da qualidade ambiental de produtos, serviços e do ambiente de trabalho nas organizações, possuindo caráter multidisciplinar, alocando corretamente os recursos disponíveis (MENDES, 2005).

De forma simplificada, o trabalho de um gestor ambiental consiste em: identificar os aspectos ambientais significativos (capazes de provocar relevante impacto ambiental); especificar formas de mitigação e de controle de tais aspectos; e implantar e manter a solução mais sustentável que minimize os impactos negativos causados ao meio ambiente (ADISSI; ALMEIDA NETO, 2013). A gestão ambiental explicita a necessidade de desenvolvimento de ações visando a minimização do consumo de recursos naturais e a redução da geração de poluentes, evitando multas ambientais. Ademais, incrementa a implantação de políticas que visam o desenvolvimento sustentável.

No caso da gestão pública, construir uma cultura para a adoção de práticas mais sustentáveis requer o compromisso das instituições e dos servidores públicos que nelas trabalham, sendo essenciais ações, projetos, programas e políticas governamentais nos níveis municipais, estaduais e federal (CORAZZA; BONACELLI; FRACALANZA, 2013). A Administração Pública não participa da economia apenas regulando mediante leis, incentivos e subvenções, mas também atuando ativamente no mercado. Assim como nas organizações privadas, ela realiza a compra de produtos, contrata serviços e obras. Portanto, ela deve assumir sua responsabilidade quanto às questões ambientais (ROSSATO; VAN BELLEN, 2011).

No Brasil, as compras públicas movimentam cerca de $13 \%$ do PIB brasileiro, o que mostra o grande poder de contratação da Administração Pública (FNDE, 2017). 
Com isso, o setor público brasileiro poderia desempenhar papel fundamental na mudança para padrões de consumo sustentáveis, estimulando ainda a inovação tecnológica.

As Instituições de Ensino Superior (IES), assim como todas as organizações, sofrem uma crescente pressão por mudanças em suas relações com o meio ambiente. Algumas delas já tentam traçar esse caminho por meio de uma adequada gestão ambiental. Tauchen et al. (2005) e Otero (2010) enxergam nas IES um agente de liderança na promoção da sustentabilidade ambiental, pois são elas que formam os futuros tomadores de decisão.

Há duas correntes principais de pensamento que se referem ao papel das IES no tocante ao desenvolvimento sustentável. A primeira destaca a questão educacional como prática fundamental para que as IES possam contribuir na qualificação de seus egressos, formando cidadãos responsáveis na relação com o meio ambiente. A segunda corrente ressalta a postura de algumas IES na implementação de sistemas de gestão ambiental (SGAs) em seus campi universitários, como modelos e exemplos práticos de gestão sustentável para a sociedade (TAUCHEN; BRANDLI, 2006).

No entanto, ainda há restrição em relação às práticas de gestão ambiental nas IES de uma forma geral, apesar de algumas se preocuparem com a sustentabilidade no ensino e nas próprias práticas ambientais, demonstrando coerência, já que estas devem praticar aquilo que ensinam (TAUCHEN; BRANDLI, 2006).

Kraemer (2005) afirma que os trabalhos desenvolvidos dentro das IES possuem um efeito multiplicador, pois cada agente que é atraído pelas boas ideias de sustentabilidade acaba influenciando os demais atores da sociedade.

Dessa forma, a implementação de práticas em gestão ambiental nas IES possui fortes motivações: os campi universitários se assemelham a pequenos núcleos urbanos, envolvendo atividades de ensino, pesquisa e extensão em conjunto com atividades de bares, restaurantes, alojamentos, centros de convivência, dentre outras. O campus ainda necessita de uma infraestrutura básica para seu funcionamento, como redes de abastecimento de água e energia, redes de saneamento e coleta de águas pluviais e vias de acesso.

Como consequência de tais atividades, há geração de resíduos sólidos e efluentes líquidos, consumo de recursos naturais, ou seja, a visão industrial de inputs e outputs (TAUCHEN; BRANDLI, 2006).

Há nas IES, por exemplo, enorme quantidade de produtos químicos nos laboratórios, os quais, quando utilizados, podem gerar grande variedade de efluentes, o que dificulta o seu tratamento (GERBASE et al., 2005; OLIVEIRA JUNIOR, 2012). Vaz et al. (2010) e Oliveira Junior (2012) complementam que, na maioria das IES, a gestão de resíduos químicos inexiste, até pela ausência de fiscalização dos órgãos competentes, e assim o descarte inadequado continua sendo praticado.

Este artigo visa identificar práticas de gestão ambiental presentes em instituições públicas de ensino superior. A relevância deste estudo está no fato de que a adoção de medidas para a redução dos impactos ambientais das organizações, além de constituírem exercícios de responsabilidade social, podem gerar economia de recursos financeiros. O setor público, em especial as IES, como 
promotor do bem-estar da sociedade, deve implantar boas práticas em gestão ambiental.

\section{METODOLOGIA}

Para o desenvolvimento deste artigo, utilizou-se a técnica de revisão narrativa, que consiste em identificar e analisar publicações amplas, apropriadas para descrever e discutir o desenvolvimento de um tema. Tais revisões, em geral, não informam a metodologia para busca das referências, nem quais os critérios utilizados na avaliação e seleção dos trabalhos. Em sua essência, constituem uma análise da literatura publicada na visão do autor (ROTHER, 2007).

Foram realizadas buscas por artigos, relatórios, legislações e outras publicações que versassem sobre o tema deste trabalho. A partir dos estudos encontrados, as pesquisas iam se expandindo, consultando-se também os trabalhos ali citados como referência.

\section{AGENDA AMBIENTAL DA ADMINISTRAÇÃO PÚBLICA (A3P)}

O Ministério do Meio Ambiente (MMA) desenvolveu, em 1999, ainda como projeto, a Agenda Ambiental na Administração Pública (A3P). Buscava-se revisar padrões de produção e consumo, além da adoção de novos referenciais de sustentabilidade ambiental nas instituições da Administração Pública. Dois anos mais tarde, a A3P consolidou-se como um programa, com o objetivo de construir uma nova cultura institucional nas organizações públicas (MMA, 2009).

De acordo com o documento elaborado pelo MMA (2018d), a A3P possui quinze objetivos básicos, a saber: I - Apoiar os órgãos públicos na criação e implementação de ações de responsabilidade socioambiental; II - Sensibilizar os servidores para a necessidade de preservação dos bens naturais; III - Estimular a construção de uma cultura institucional que agregue valores, atitudes e comportamentos consoantes com a responsabilidade socioambiental; IV Incentivar os órgãos públicos a adotarem medidas que visem à redução de impactos socioambientais negativos decorrentes de suas atividades; $V$ - Aumentar a eficiência da gestão, promovendo a economia de recursos naturais e de gastos institucionais; VI - Promover a atualização sistemática do conhecimento e a modernização de conceitos, instrumentos, tecnologias e metodologias, referentes ao campo da sustentabilidade; VII - Promover a transparência no serviço público; VIII - Garantir a acessibilidade nos órgãos públicos às pessoas portadoras de deficiência ou com mobilidade reduzida; IX - Estimular e apoiar ações de defesa do meio ambiente; X - Facilitar o acesso das instituições públicas ao Programa A3P; XI - Estimular ações de cooperativismo, solidariedade, respeito, compromisso profissional e ético; XII - Capacitar e sensibilizar os gestores públicos quanto à responsabilidade socioambiental; XIII - Colaborar para a melhoria da qualidade de vida dos servidores; XIV - Incentivar às ações coletivas e às decisões democráticas; e XV - Promover a produção e o consumo sustentáveis.

Apesar de não haver obrigatoriedade legal quanto à adesão à A3P pelos órgãos públicos, é possível perceber a sua evolução através dos anos no Gráfico 1. 


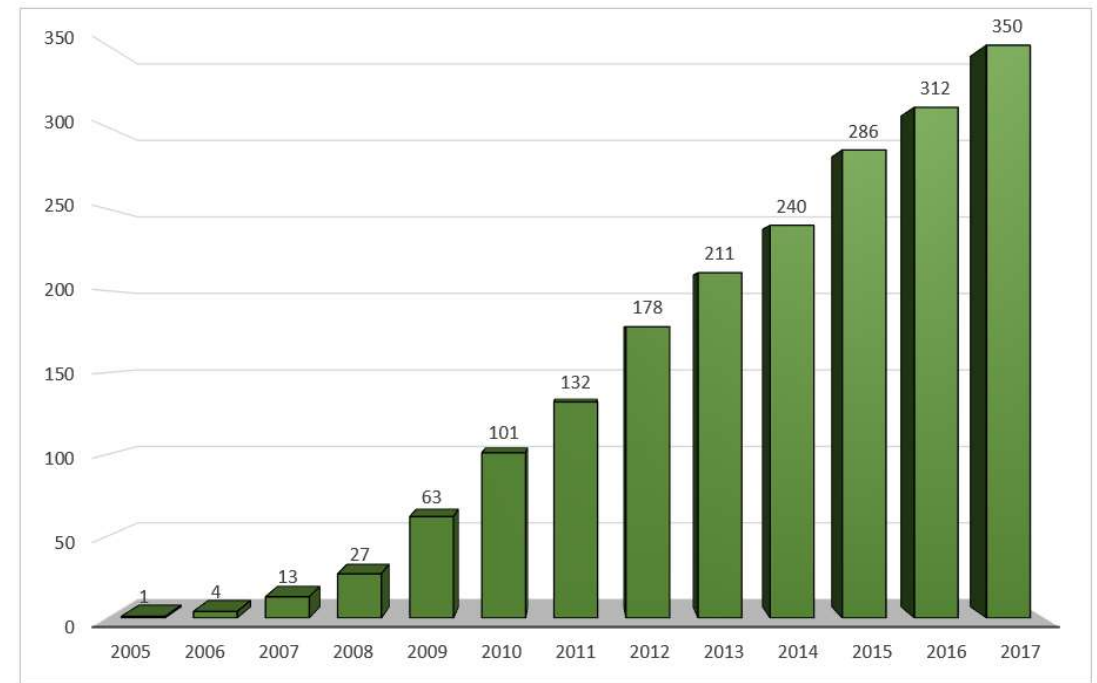

Fonte: MMA, 2018b

Há também um canal de comunicação permanente, chamado Rede A3P, utilizado para trocar informações, experiências e intercâmbio técnico entre os participantes, difundindo temas relevantes à agenda ambiental. Assim, ainda que a instituição interessada não tenha o Termo de Adesão formalizado junto ao MMA, é possível se inteirar dos tópicos da A3P de forma a promover as mudanças voltadas ao desenvolvimento de ações e programas de gestão ambiental (MMA, 2009).

O Gráfico 2 ilustra a evolução dos participantes da Rede A3P e o Gráfico 3 mostra a distribuição por esfera do governo.

Gráfico 2 - Evolução às adesões da Rede A3P

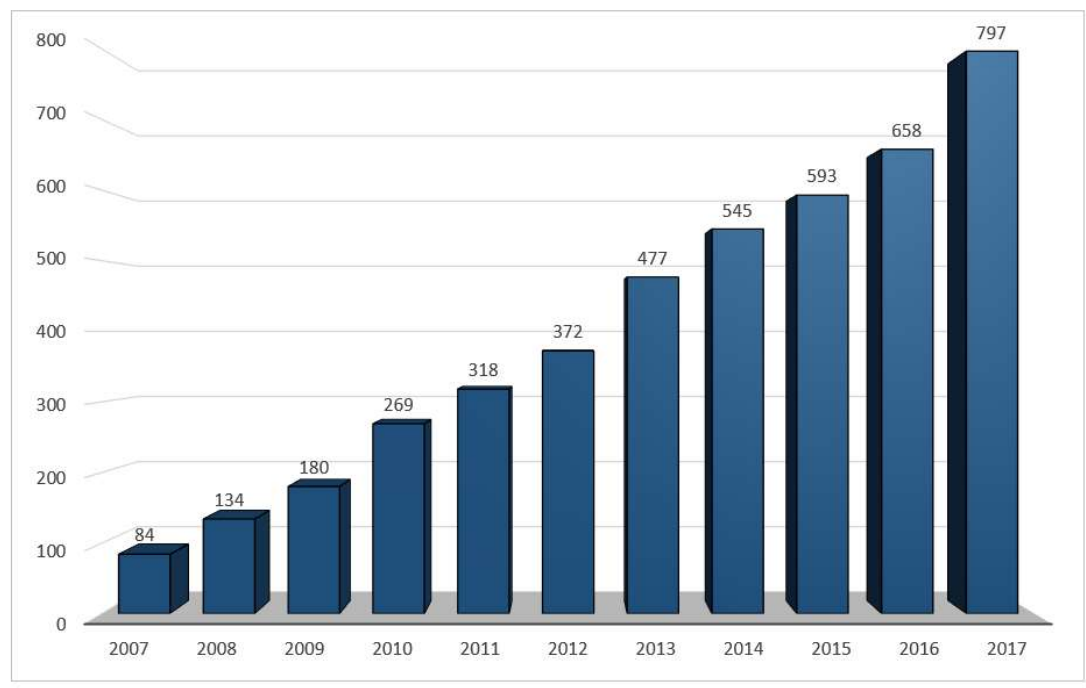

Fonte: MMA, 2018b 


\section{Gráfico 3 - Adesão à Rede A3P: distribuição por esfera do governo}

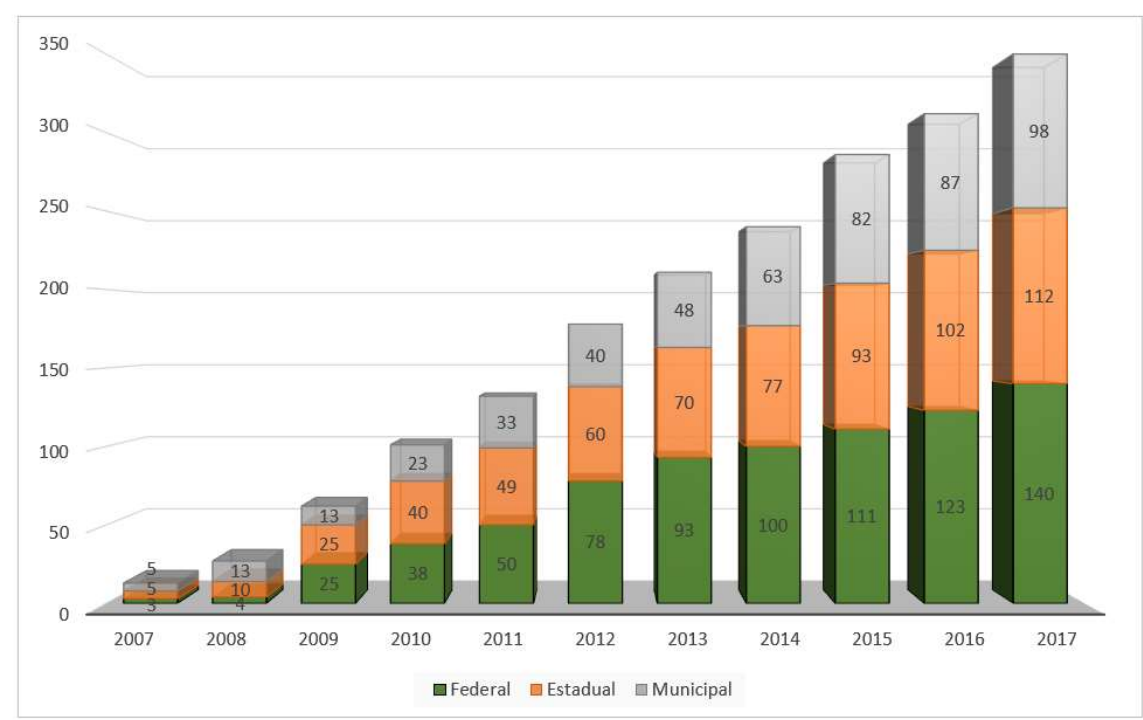

Fonte: MMA, 2018b

Para o cumprimento de seus objetivos, a A3P foi estruturada em seis eixos temáticos, apontados no Quadro 1, juntamente com seus fundamentos básicos.

Quadro 1 - Eixos Temáticos da A3P

\begin{tabular}{|c|c|}
\hline Eixos Temáticos & Fundamentos \\
\hline $\begin{array}{l}\text { Uso Racional dos } \\
\text { Recursos Naturais e } \\
\text { Bens Públicos }\end{array}$ & $\begin{array}{l}\text { Usar racionalmente os recursos naturais e bens públicos significa } \\
\text { utilizá-los evitando o seu desperdício. Este eixo trata do uso } \\
\text { racional de energia, água e madeira, além do consumo de } \\
\text { matérias de expediente, como papel, copos plásticos e outros. }\end{array}$ \\
\hline $\begin{array}{l}\text { Gestão Adequada } \\
\text { dos Resíduos } \\
\text { Gerados }\end{array}$ & $\begin{array}{l}\text { A gestão adequada dos resíduos passa pela adoção da política } \\
\text { dos } 5 R^{\prime} \text { s: Repensar, Reduzir, Reutilizar, Reciclar e Recusar. } \\
\text { Prioritariamente deve-se pensar em reduzir o consumo e } \\
\text { combater o desperdício, para só então destinar adequadamente } \\
\text { o resíduo gerado. }\end{array}$ \\
\hline $\begin{array}{l}\text { Qualidade de Vida no } \\
\text { Ambiente de } \\
\text { Trabalho }\end{array}$ & $\begin{array}{l}\text { A qualidade de vida no ambiente de trabalho busca facilitar e } \\
\text { satisfazer as necessidades do trabalhador, por meio de ações que } \\
\text { visem seu desenvolvimento pessoal e profissional. }\end{array}$ \\
\hline $\begin{array}{c}\text { Sensibilização e } \\
\text { Capacitação }\end{array}$ & $\begin{array}{l}\text { A sensibilização visa estabelecer a responsabilidade } \\
\text { socioambiental no corpo de servidores. A capacitação busca } \\
\text { contribuir para o desenvolvimento de competências } \\
\text { institucionais e individuais para que os servidores desenvolvam } \\
\text { atitudes, visando a melhoria de suas atividades. }\end{array}$ \\
\hline $\begin{array}{l}\text { Licitações } \\
\text { Sustentáveis }\end{array}$ & $\begin{array}{l}\text { A Administração Pública deve buscar a responsabilidade } \\
\text { socioambiental nas suas compras. Licitações sustentáveis são } \\
\text { importantes para a preservação ambiental e apresentam uma } \\
\text { melhor relação custo/benefício a médio ou longo prazo quando } \\
\text { se comparam às que se valem apenas do menor preço. }\end{array}$ \\
\hline $\begin{array}{l}\text { Construções } \\
\text { Sustentáveis }\end{array}$ & $\begin{array}{l}\text { Construção sustentável é um conceito que denomina um } \\
\text { conjunto de medidas adotadas durante todas as etapas da obra } \\
\text { que visam a sustentabilidade da edificação. Através da adoção } \\
\text { dessas medidas é possível minimizar os impactos negativos sobre } \\
\text { o meio ambiente além de promover a economia dos recursos } \\
\text { naturais e a melhoria na qualidade de vida dos seus ocupantes. }\end{array}$ \\
\hline
\end{tabular}

Fonte: Adaptado de MMA (2009, 2018c) 
No entanto, para que a A3P seja efetiva, é fundamental a mobilização e a sensibilização dos servidores públicos e estudantes, no caso das IES, bem como o planejamento e monitoramento das ações, com o uso de indicadores de desempenho. Atividades ambientalmente corretas devem ser estimuladas, a exemplo da implantação de coleta seletiva, a substituição de copos descartáveis por canecas reutilizáveis e o uso de aparelhos eletrônicos mais eficientes. A estas somam-se as práticas cotidianas, como apagar as luzes ao sair e economizar água.

Tal agenda possui um efeito multiplicador e transformador, pois se baseia na educação ambiental, na mudança de cultura e de hábitos por parte dos servidores públicos. Tal mudança pode ser estender para o restante da sociedade, às suas residências, ajudando na melhoria da imagem da Administração Pública, indo de encontro à visão estereotipada e presente do estigma de excesso de gastos nos órgãos públicos especialmente no caso das IES, onde o estudante pode se tornar o agente de difusão de tais práticas.

\section{Pilar legal da A3P}

A legislação ambiental brasileira, sustentáculo da sustentabilidade no país, prevê a manutenção e conservação do meio ambiente, assim como observa a indispensabilidade em adotar uma nova ética social. Almeja ainda a racionalidade da dimensão econômica, buscando a manutenção do equilíbrio ecológico, garantia da saúde, qualidade de vida e bem-estar econômico, social e ambiental do povo brasileiro. A questão ambiental é parte da agenda pública, exigindo a complementaridade e a interação entre as mais diversas ações do poder público, que possibilitarão o desenvolvimento sustentável do país (MMA, 2009).

O Quadro 2 expõe as principais legislações que embasam a A3P. 
Quadro 2 - Principais Legislações que embasam a A3P

\begin{tabular}{|c|c|}
\hline Norma Legal & Conteúdo \\
\hline Lei Federal n.ㅇ 6.938/81 & $\begin{array}{l}\text { Institui a Política Nacional do Meio Ambiente. Considerada } \\
\text { um marco histórico no desenvolvimento do direito } \\
\text { ambiental, a lei estabelece definições legais sobre os } \\
\text { seguintes temas: meio ambiente, degradação da qualidade } \\
\text { ambiental, poluição, poluidor e recursos ambientais. Entre } \\
\text { os muitos avanços visando a proteção ambiental destaca-se } \\
\text { na Lei a exigência de Estudo prévio de Impacto Ambiental } \\
\text { (EIA) e o seu respectivo relatório (RIMA). }\end{array}$ \\
\hline $\begin{array}{l}\text { Constituição Federal de } \\
1988\end{array}$ & $\begin{array}{l}\text { O artigo } 225 \text { afirma o direito da sociedade a um meio } \\
\text { ambiente ecologicamente equilibrado e afirma que cabe à } \\
\text { coletividade e ao poder Público defendê-lo e preservá-lo. }\end{array}$ \\
\hline Lei Federal $n$ & $\begin{array}{l}\text { Lei dos crimes ambientais. Dispõe sobre a proteção efetiva } \\
\text { do meio ambiente. }\end{array}$ \\
\hline $\begin{array}{l}\text { Decreto Federal n.o } \\
5.940 / 2006\end{array}$ & $\begin{array}{l}\text { Estabelece a exigência de separação dos resíduos } \\
\text { recicláveis dos órgãos e entidades da Administração Pública } \\
\text { federal direta e indireta, e sua destinação às associações e } \\
\text { cooperativas dos catadores de materiais recicláveis. }\end{array}$ \\
\hline $\begin{array}{l}\text { Lei Federal n.ㅇ } \\
12.187 / 2009\end{array}$ & Institui a Política Nacional de Mudanças Climáticas. \\
\hline $\begin{array}{l}\text { Lei Federal n.ㅇ } \\
12.349 / 2010\end{array}$ & $\begin{array}{l}\text { Altera a Lei no 8.666/93 (a Lei das licitações). A promoção } \\
\text { do desenvolvimento nacional sustentável se torna objetivo } \\
\text { das licitações. }\end{array}$ \\
\hline $\begin{array}{l}\text { Lei Federal n.o } \\
12.305 / 2010\end{array}$ & Institui a Política Nacional de Resíduos Sólidos (PNRS). \\
\hline $\begin{array}{l}\text { Instrução Normativa n.o } \\
1 / 2010 \text { do Ministério do } \\
\text { Planejamento Orçamento } \\
\text { e Gestão (MPOG) }\end{array}$ & $\begin{array}{l}\text { Estabelece critérios de sustentabilidade ambiental na } \\
\text { aquisição de bens, contratação de serviços ou obras na } \\
\text { Administração Pública Federal. }\end{array}$ \\
\hline $\begin{array}{c}\text { Lei Federal } n . \text { o } \\
12.462 / 2011\end{array}$ & Estabelece o Regime diferenciado de contratações públicas. \\
\hline $\begin{array}{l}\text { Recomendação CONAMA } \\
\text { n. } .12 / 2011\end{array}$ & $\begin{array}{l}\text { Indica aos órgãos e entidades do Sistema Nacional do Meio } \\
\text { Ambiente (Sisnama) a adoção de normas e padrões de } \\
\text { sustentabilidade. }\end{array}$ \\
\hline $\begin{array}{l}\text { Decreto Federal n.으 } \\
7.746 / 2012\end{array}$ & $\begin{array}{l}\text { Determina a adoção de iniciativas, dentre elas a } \mathrm{A} 3 \mathrm{P} \text {, } \\
\text { referentes ao tema da sustentabilidade pelos órgãos e } \\
\text { entidades federais bem como suas vinculadas. }\end{array}$ \\
\hline $\begin{array}{l}\text { Instrução Normativa n.o } \\
\text { 10/2012 do MPOG }\end{array}$ & $\begin{array}{l}\text { Estabelece as regras para elaboração dos Planos de Gestão } \\
\text { de Logística Sustentável pela Administração Pública federal } \\
\text { bem como suas vinculadas. }\end{array}$ \\
\hline
\end{tabular}

Fonte: adaptado de MMA (2018a)

\section{DESENVOLVIMENTO DE POLÍTICAS DE GESTÃO AMBIENTAL EM INSTITUIÇÕES PÚBLICAS DE ENSINO SUPERIOR BRASILEIRAS}

\section{Casos de aplicação da gestão ambiental em IES}

A Universidade Federal de Santa Catarina possui uma Coordenadoria de Gestão Ambiental, criada em 1996, ligada diretamente à Reitoria. Trata-se de caso de resultados positivos de proteção ambiental dentro de uma universidade 
(MENDES, 2005), criando um ambiente privilegiado para se utilizar o ensino como forma de buscar continuamente a melhora da relação homem-meio ambiente, fazendo a comunidade participar da proposta, almejando melhora na qualidade de vida pelo conhecimento (RIBEIRO et al., 2005).

Ainda no estado de Santa Catarina pode-se citar o caso da Universidade Regional de Blumenau (FURB). Em março de 1998, foi criado o Comitê de Implantação do SGA, com representantes de toda comunidade universitária. O objetivo era identificar os problemas ambientais da IES, buscando eliminar ou reduzir os tais problemas. Foi elaborada a Política Ambiental da FURB e dado início ao Planejamento Ambiental por esse Comitê, o que culminou com a criação do SGA da IES em 1999 (BUTZE; PEREIRA; NOUBAUER, 2001).

Pode-se mencionar também o caso da Universidade Federal do Rio Grande do Sul (UFRGS). Inicialmente gerou-se um diagnóstico a respeito de resíduos gerados e suas destinações, obtendo importantes informações. Ao se realizar a análise dos dados obtidos, constatou-se que havia iniciativas pontuais que objetivavam a melhoria dos aspectos ambientais da universidade. Um grupo de estudantes do curso de Engenharia de Materiais planejou um sistema de Gerenciamento de Resíduos Sólidos Urbanos (GRSU), que foi implementado em 2004. Nos primeiros meses, o projeto atingiu seus objetivos, porém nos meses seguintes os estudantes envolvidos no projeto se afastaram e, aliado a isso, houve falta de apoio da alta administração da universidade. Com isso, o projeto foi se desestruturando.

Ao se analisar o caso da UFRGS, percebem-se barreiras na implementação do SGA, podendo-se citar: a falta de informação da sociedade sobre práticas sustentáveis; diversos colaboradores da instituição não valorizam o meio ambiente da forma devida; e a não percepção da universidade como fonte de emissão de poluentes (RIBEIRO et al., 2005).

O Reitor da Universidade Estadual de Campinas (UNICAMP), por meio da Resolução GR no. 41/2014, posteriormente substituída pela Resolução GR no. 29/2015, criou o órgão chamado Grupo Gestor Universidade Sustentável (GGUS), com o objetivo de planejar, desenvolver, viabilizar e gerenciar as ações, projetos e programas sobre sustentabilidade socioambiental. A decisão decorreu da visão estratégica de instituir na universidade um "Sistema de Gestão Universidade Sustentável" e uma "Política Universidade Sustentável", fundamentadas no conceito amplo de sustentabilidade. O GGUS incorporou algumas atividades que já existiam como o Grupo Gestor Ambiental e a Célula Operacional de Resíduos (UNICAMP, 2017).

Dentre agraciados com o "Prêmio A3P 2018", pode-se citar a iniciativa "Gerenciamento de Resíduos Sólidos na Universidade Estadual do Maranhão (UEMA): Projeto Nosso Papel". Tal programa visava a melhoria da gestão do papel utilizado na UEMA, baseando-se nos princípios preconizados pela política dos $5 R^{\prime}$ s (reduzir, repensar, reaproveitar, reciclar e recusar o consumo do que gera impacto ambiental) e da A3P. No período de janeiro de 2015 a setembro de 2017, foram coletados e destinados $12.429,74 \mathrm{~kg}$ de papéis para a reciclagem. O projeto contou com diversas ações, como por exemplo: foi firmada parceria com a Companhia Energética do Maranhão (CEMAR), o que possibilitou trocar resíduos recicláveis por bônus na fatura de energia elétrica; em novembro de 2016, instalou-se no campus o Ecoponto Solidário, para servir de apoio à uma cooperativa de reciclagem (MMA, 2018e). 
Outro premiado pela A3P em 2018 foi o "Projeto de Recuperação e Educação Ambiental no Bosque do CFH da Universidade de Santa Catarina (UFSC)". Iniciado em 2015, o projeto promoveu o plantio de mais de 200 mudas de espécies nativas e a retirada de 80 exemplares de eucaliptos, que prejudicavam o desenvolvimento de outras árvores. Como consequência dessas ações, pode-se apontar a diminuição das áreas críticas de erosão. Houve ainda a recomposição da mata ciliar em trechos nevrálgicos dos riachos (MMA, 2018f).

Feil, Strasburg e Naime (2015) buscaram estudos sobre a gestão ambiental em IES brasileiras. Os resultados estão sistematizados no Quadro 3, complementados por dados obtidos na presente pesquisa, em consulta às páginas eletrônicas das instituições:

\begin{tabular}{|c|c|c|}
\hline IES & UF da IES & Ano de implantação da gestão ambiental \\
\hline UEFS & BA & 1992 \\
\hline UnB & DF & 1996 \\
\hline $\operatorname{UFSC}(*)$ & SC & 1996 \\
\hline UFRJ & RJ & 1998 \\
\hline USP & SP & 1998 \\
\hline UFPR & PR & 1998 \\
\hline FURB $(*)$ & SC & 2000 \\
\hline UFRGS & RS & 2001 \\
\hline UERJ & RJ & 2003 \\
\hline UFSM $(*)$ & RS & 2004 \\
\hline UFTPR & PR & 2005 \\
\hline UFPEL & RS & 2005 \\
\hline UNESP & SP & 2006 \\
\hline UNICAMP & SP & 2007 \\
\hline UFAL & $\mathrm{AL}$ & 2009 \\
\hline UFLA & MG & 2009 \\
\hline UFCSPA & RS & 2010 \\
\hline UEMA (*) & MA & 2010 \\
\hline FURG & RS & 2012 \\
\hline UFU & MG & 2012 \\
\hline UFPB $(*)$ & PB & 2013 \\
\hline UFPE $\left({ }^{*}\right)$ & PE & 2014 \\
\hline UFS $(*)$ & SE & 2015 \\
\hline UNIFESP & SP & 2015 \\
\hline CEFET-RJ (*) & RJ & 2016 \\
\hline UNIVASF $\left({ }^{*}\right)$ & $\mathrm{PE}$ & 2016 \\
\hline UFU $\left({ }^{*}\right)$ & MG & 2017 \\
\hline UFCA $(*)$ & $\mathrm{CE}$ & 2020 \\
\hline
\end{tabular}

$\left({ }^{*}\right)$ Instituiçoes que aderiram formalmente à A3P

Fonte: adaptado de Feil, Strasburg e Naime (2015) e atualizado pelo autor

Observa-se, no entanto, que apesar da implantação de práticas de Gestão Ambiental em diversas IES brasileiras, há falta de análises que demonstrem a efetividade dessas ações, tanto na literatura quanto na página eletrônica dessas instituições, bem como os avanços obtidos desde então. 
É possível ainda encontrar diversos estudos propondo ações de gestão ambiental em órgãos públicos brasileiros. A seguir serão relatados alguns que se encontram publicados na literatura especializada.

Mendes (2005) propôs diretrizes para implantação de um SGA na Universidade Estadual do Rio de Janeiro (UERJ), mais especificamente no Campus Francisco Negrão de Lima. Foram realizados levantamentos da estrutura organizacional da instituição, consumo de energia e água, e produção de resíduos comuns, visando construir as diretrizes da Gestão Ambiental, tais como a adoção de Princípios, Política Ambiental e algumas propostas de curto e médio prazo.

Em sua tese de doutorado, Mendes (2011) modelou o Sistema de Gerenciamento Integrado de Resíduos Perigosos (SIGIRPE), validando-o por meio de sua aplicação em estudo piloto nos laboratórios dos Institutos de Química e Biologia da UERJ. Os resultados da pesquisa permitiram conhecer a dinâmica e os problemas existentes nos laboratórios, bem como verificar a potencialidade do modelo. $\mathrm{O}$ autor concluiu que o SIGIRPE pode ser aplicado a outros contextos desde que seja adequado para tal fim.

Andrade e Pimenta (2009) propuseram uma política ambiental para a unidade sede do Instituto Federal do Rio Grande do Norte (IFRN). Foram levantados todos os programas, processos e projetos relacionados à temática ambiental na organização. A política ambiental foi desenvolvida contando com a participação efetiva da comissão de gestão ambiental da unidade sede e contempla sua visão e comprometimento em relação das ações de gestão ambiental da instituição. Ela contém oito diretrizes que tratam respectivamente de: Controle Eficiente de Água e Energia, Uso Racional de Materiais de Consumo, Gerenciamento de Resíduos sólidos, Gerenciamento das Obras Civis, Gerenciamento de Áreas Verdes, Educação Ambiental, Suporte de Recursos e Requisitos Legais.

Finger, Moretto Neto e Vieira (2010) pesquisaram a gestão ambiental no Laboratório de Camarões Marinhos - LCM, da Universidade Federal de Santa Catarina (UFSC). Verificou-se a importância da disseminação dos conhecimentos sobre os processos dentro da organização e indicou-se a responsabilidade da universidade na gestão ambiental do laboratório.

Rohrich (2014) realizou um estudo de caso na Universidade Federal do Paraná (UFPR), que possui seis campi, todos eles subordinados às diretrizes ambientais da Divisão de Gestão Ambiental (DGA), órgão da universidade responsável por gerir as ações relativas ao tema. $O$ trabalho descreveu o processo de gestão ambiental e o gerenciamento dos resíduos gerados no Campus Litoral da UFPR, o qual atende aos requisitos mínimos obrigatórios na legislação quanto à separação e descarte de resíduos reciclados e perigosos. Entretanto, a comunidade acadêmica não possui amplas informações a esse respeito, e a maioria desconhece a política ambiental da UFPR. O Campus Litoral não possui um sistema de gestão ambiental formalizado, sendo que as práticas ambientais não podem ser consideradas prioridade estratégica no tripé ensino, pesquisa e extensão.

Moraes et al. (2014) planejaram um sistema de gestão ambiental com base na norma ISO 14001 para uma biblioteca de uma das unidades da UNESP, visando estimular a busca pela melhoria contínua e a sustentabilidade na instituição de ensino. Os resultados mostraram que dentre os benefícios que a organização teria envolveriam redução dos gastos com energia e água. 


\section{DISCUSSÃO}

Guthrie e Parker (1989) destacaram que as organizações são legitimadas baseando-se no fato de que operam na sociedade por meio de um contrato social.

À luz da teoria da legitimidade, é fundamental o papel dos gestores em perceber como a organização é vista pela sociedade. De alguma forma as práticas organizacionais podem estar rompendo com esse contrato social, carecendo de estratégias de correção que deverão ser divulgadas a fim de mudar a percepção da sociedade (DEEGAN, 2002). Dessa forma, estratégias de divulgação podem inclusive reverter um quadro negativo da organização, ou ao menos amenizá-lo, perante aos seus interessados. Portanto, é de suma importância evidenciar uma imagem positiva, utilizando de forma correta as estratégias de legitimação.

Assim, a legitimidade associa-se à imagem que a organização quer passar de si para a sociedade. O poder público influencia a cultura do país, especialmente pela ação de seus gestores. Nesse passo, a implantação de uma adequada gestão ambiental é fundamental na busca pela Responsabilidade Socioambiental dos órgãos públicos, estimulando a legitimidade das ações públicas.

Os gestores públicos, quando decidem gerir adequadamente as questões ambientais, cumprem com sua obrigação constitucional quanto à eficiência publica, além de seu compromisso socioambiental previsto no artigo 225 da Constituição da República, que divide entre Poder Público e coletividade a missão de defender e preservar o meio ambiente (BRASIL, 1988).

Para Drummond e Barros-Platiau (2006) há alguns pilares que permitem a uma gestão ambiental ser efetiva. O primeiro é haver uma legislação ambiental sólida. O segundo consiste na existência de instituições públicas fortes, que permitam a implementação de tal legislação. E o terceiro envolve a legitimidade social, que atua como propulsor incentivador das mudanças.

Percebe-se que o Brasil possui os pilares que permitem uma gestão ambiental efetiva, o que favorece a evolução, a divulgação e a implementação de políticas tais como da A3P pelas mais variadas instituições públicas.

\section{CONSIDERAÇÕES FINAIS}

Como pode ser visto neste trabalho, as discussões dirigidas para o desenvolvimento sustentável vêm ganhando um espaço crescente na sociedade moderna. A Administração Pública, como não poderia deixar de ser, não fica de fora dessa realidade, propondo programas e políticas de estímulo da responsabilidade socioambiental no setor governamental.

Este estudo teve como objetivo apresentar práticas de gestão ambiental presentes em IES públicas.

Muitos órgãos públicos brasileiros, dentre eles as IES, vêm enfrentando dificuldades financeiras, justificados pela "crise econômica" que o país enfrenta no atual momento. Apesar de tudo isso, é inegável a importância de tais órgãos na construção de um país melhor e mais justo. Com isso, pode ser reforçada a importância da inclusão de iniciativas em gestão ambiental em tais instituições. Destacam-se dentre as vantagens: economia com água, energia e materiais de 
consumo; conformidade com as legislações vigentes; melhora na imagem da instituição; e geração de oportunidade de estudos e pesquisas.

Dentre as limitações da pesquisa, pode-se citar que, pelo fato de constituir uma revisão narrativa, não possui uma metodologia que permita a reprodução dos dados.

Sugere-se para trabalhos futuros:

- verificar a presença de critérios de sustentabilidade ambiental em editais de licitação, a fim de avaliar as propostas apresentadas pelos licitantes;

- estudar a adaptação do mercado quanto às novas exigências de consumo da Administração Pública;

- examinar a adequação da gestão dos resíduos sólidos gerados nas atividades desenvolvidas pela Administração Pública, especialmente quanto à Coleta Seletiva e à logística reversa;

- avaliar os ganhos das instituições que aderiram a práticas em gestão ambiental. 


\title{
Narrative review on environmental management practices in brazilian public higher education institutions
}

\begin{abstract}
Given the importance of the public sector to the environmental issue in Brazil, particularly from Higher Education Institutions (HEIs), the identification and analysis of environmental management practices present in Brazilian public HEls, based on the narrative review technique. The existence of practices that aim to improve their relationship with the environment were discovered in some of these institutions. Proposals to expand environmental management in HEls were also observed. The growing adherence to the Environmental Agenda in Public Administration (A3P) by public bodies, especially by HEls, as well as the environmental management practices identified, showed that discussions and actions aimed at sustainable development are increasing in Brazilian society. The implementation of an adequate environmental management proved to be fundamental in the search for Socio-Environmental Responsibility of public HEls, stimulating the legitimacy of actions in these institutions, in the context considered.
\end{abstract}

KEYWORDS: Environmental management. Sustainable development. Higher Education Institutions. Environmental Agenda in Public Administration. A3P. 


\section{REFERÊNCIAS}

ADISSI, Paulo José; ALMEIDA NETO, José Adolfo de. Conceitos básicos da gestão ambiental. In: ADISSI, Paulo José; PINHEIRO, Francisco Alves; CARDOSO, Rosangela da Silva (Org.). Gestão Ambiental de Unidades Produtivas. Rio de Janeiro: Elsevier, 2013. p. 1-18.

ANDRADE, Jorge Henrique Bezerra; PIMENTA, Handson Claudio Dias. Gestão Ambiental no IFRN - Implementação de uma Política Ambiental Considerando o Papel das Instituições de Ensino no Desenvolvimento Sustentável. Holos, Natal, v. 2, p.73-93, out. 2009.

BRASIL. Constituição (1988). Constituição Da República Federativa do Brasil de 1988. Brasília, 1988.

CORAZZA, Rosana Icassatti; BONACELLI, Maria Beatriz Machado; FRACALANZA, Paulo Sérgio. Três visões sobre sustentabilidade e implicações para a avaliação em ciência, tecnologia e inovação. Revista Tecnologia e Sociedade, Curitiba, v. 9, n. 18, p.115, dez. 2013.

DEEGAN, Craig. Introduction: The legitimising effect of social and environmental disclosures - a theoretical foundation. Accounting, Auditing \& Accountability Journal, [s.I.], v. 15, n. 3, p.282-311, ago. 2002.

DRUMMOND, Jose; BARROS-PLATIAU, Ana Flavia. Brazilian Environmental Laws and Policies, 1934-2002: A Critical Overview. Law \& Policy, [s.I.], v. 28, n. 1, p.83-108, jan. 2006.

FEIL, Alexandre André; STRASBURG, Virgílio José; NAIME, Roberto Harb. Meta-análise das publicações científicas de IES brasileiras com Sistema de Gestão Ambiental. Revista Gestão Universitária na América Latina - Gual, Florianópolis, v. 8, n. 1, p.214-235, jan. 2015.

FINGER, Luciane; MORETTO NETO, Luís; VIEIRA, Bruna Ghizoni. Análise do sistema de gestão ambiental do laboratório de camarões marinhos da Universidade Federal de Santa Catarina - UFSC. Revista de Ciências da Administração, Florianópolis, v. 12, n. 27 , p.208-231, mai./ago. 2010.

FNDE - FUNDO NACIONAL DE DESENVOLVIMENTO DA EDUCAÇÃO. Sobre Compras Governamentais. 2017. Disponível em: <https://www.fnde.gov.br/acoes/compras- 
governamentais/sobre-compras-governamentais>. Acesso em: 27 dez. 2018.

GERBASE, Annelise E. et al. Gerenciamentos de resíduos químicos em instituições de ensino e pesquisa. Química Nova, São Paulo, v. 28, n. 1, p.3-3, jan./fev. 2005.

GUTHRIE, James; PARKER, Lee D. Corporate Social Reporting: A Rebuttal of Legitimacy Theory. Accounting and Business Research, [s.I.], v. 19, n. 76, p.343-352, set. 1989.

KAHLAU, Camila et al. Identificação de áreas temáticas para subsidiar pesquisa sobre sustentabilidade em indústrias. Revista Tecnologia e Sociedade, Curitiba, v. 10, n. 20, p.49-70, jul./dez. 2014.

KRAEMER, Maria Elisabeth Pereira. A contribuição do contabilista para o desenvolvimento sustentável. 2005. Disponível em: <https://www.gestiopolis.com/a-contribuicao-contabilista-para-odesenvolvimento-sustentavel/>. Acesso em: 22 dez. 2018.

MENDES, Luiz Antonio Arnaud. Diretrizes para implantação da gestão ambiental na Universidade Do Estado Do Rio De Janeiro - Campus Francisco Negrão De Lima. 2005. 134 f. Dissertação (Mestrado) - Curso de Pós-graduação em Engenharia Ambiental, Universidade do Estado do Rio de Janeiro, Rio de Janeiro, 2005.

MENDES, Luiz Antonio Arnaud. Sistema de Gerenciamento Integrado de resíduos perigosos: modelagem e validação nos laboratórios da Universidade do Estado do Rio de Janeiro. 2011. 303 f. Tese (Doutorado) - Curso de Pós-graduação em Meio Ambiente, Universidade do Estado do Rio de Janeiro, Rio de Janeiro, 2011.

MMA - Ministério do Meio Ambiente. A História da A3P. 2018a. Disponível em: <http://www.mma.gov.br/informma/item/8852>. Acesso em: 22 dez. 2018.

MMA - Ministério do Meio Ambiente. A3P em números. 2018b. Disponível em: <http://www.mma.gov.br/responsabilidadesocioambiental/a3p/a3p-em-numeros >. Acesso em: 22 dez. 2018.

MMA - Ministério do Meio Ambiente. Agenda Ambiental na Administração Pública. 5. ed. Brasília: MMA, 2009. 100 p. 
MMA - Ministério do Meio Ambiente. Construções Sustentáveis. 2018c. Disponível em: <http://www.mma.gov.br/component/k2/item/10317-eixos-temáticosconstruçõessustentáveis>. Acesso em: 22 dez. 2018.

MMA - Ministério do Meio Ambiente. Portaria $\mathrm{n}^{0}$ 3, de 27 de fevereiro de 2018. Institui as diretrizes do Programa da Agenda Ambiental na Administração Pública - Programa A3P. Brasília, 01 mar. 2018d.

MMA - Ministério do Meio Ambiente. Projeto Nosso Papel. 2018e. Disponível em: <http://a3p.mma.gov.br/wpcontent/uploads/Pr\%C3\%AAmio/7\%C2\%BAPr\%C3\%AAmio2018/Do cumentos/Projeto-_versao_final_aprovada_pela_UEMA.pdf>. Acesso em: 14 fev. 2020.

MMA - Ministério do Meio Ambiente. Recuperação e Educação Ambiental no Bosque do CFH. 2018f. Disponível em: <http://a3p.mma.gov.br/wpcontent/uploads/Pr\%C3\%AAmio/7\%C2\%BAPr\%C3\%AAmio2018/Do cumentos/Texto_revisado_-_aprovado_pela_UFSC.pdf>. Acesso em: 14 fev. 2020.

MORAES, Clauciana Schmidt Bueno de et al. Os benefícios da implantação do Sistema De Gestão Ambiental (SGA) e a aplicação na universidade. In: ENCONTRO INTERNACIONAL SOBRE GESTÃO EMPRESARIAL E MEIO AMBIENTE, 16., 2014, São Paulo. Anais... São Paulo: ENGEMA, 2014. p. 1 - 16.

OLIVEIRA JÚNIOR, Francisco de Assis. Implantação do programa de gerenciamento de resíduos químicos: caso da Universidade Federal de Lavras. 2012. 104 f. Dissertação (Mestrado) - Curso de Pós-graduação em Agroquímica, Universidade Federal de Lavras, Lavras, 2012.

OTERO, Gabriela Gomes Prol. Gestão Ambiental em Instituições de Ensino Superior: Prática dos campi da Universidade de São Paulo. 2010. 180 f. Dissertação (Mestrado) - Curso de Pósgraduação em Ciência Ambiental, Universidade de São Paulo, São Paulo, 2010.

RIBEIRO, Lauro André et al. Avaliação de barreiras para implementação de um sistema de gestão ambiental na UFRGS. In: ENCONTRO NACIONAL DE ENGENHARIA DE PRODUÇÃO, 25., 2005, Porto Alegre. Anais... Porto Alegre: ABEPRO, 2005. p. 1 - 8. 
ROHRICH, Sandra Simm. A gestão ambiental na universidade federal do paraná: Um estudo de caso sobre a gestão ambiental e o gerenciamento dos resíduos no Campus Litoral. In: ENCONTRO INTERNACIONAL SOBRE GESTÃO EMPRESARIAL E MEIO AMBIENTE, 16., 2014, São Paulo. Anais... São Paulo: ENGEMA, 2014. p. 1 - 15.

ROSSATO, Jaqueline; VAN BELLEN, Hans Michael. Licitações Sustentáveis: um Levantamento das Iniciativas Adotadas na Administração Pública. In: ENCONTRO DA ANPAD, 35., 2011, Rio de Janeiro. Anais... Rio de Janeiro: ANPAD, 2011. p. 1 - 17.

ROTHER, Edna Terezinha. Revisão sistemática $X$ revisão narrativa. Acta Paulista de Enfermagem, São Paulo, v. 20, n. 2, p.v-vi, abr./jun. 2007.

SERRA, Maurício A.; MORAES, Gustavo Inácio de. Desenvolvimento e meio ambiente: tecnologias apropriadas como o caminho para a sustentabilidade ambiental. Revista Tecnologia e Sociedade, Curitiba, v. 2, n. 2, p.133-152, mar. 2006.

TAUCHEN, Joel Antonio et al. Gestão Ambiental: Um modelo na Faculdade Horizontina - FAHOR. In: SIMPÓSIO DE ENGENHARIA DE PRODUÇÃO, 12., 2005, Bauru. Anais... Bauru: SIMPEP, 2005. p. 1 - 11.

TAUCHEN, Joel Antonio; BRANDLI, Luciana Londero. A gestão ambiental em instituições de ensino superior: modelo para implantação em campus universitário. Gestão \& Produção, São Carlos, v. 13, n. 3, p.503-515, dez. 2006.

UNICAMP - UNIVERSIDADE ESTADUAL DE CAMPINAS. Institucional. Disponível em: <http://www.cgu.unicamp.br/ggus/?page_id=83>. Acesso em: 30 out. 2017.

VAN BELLEN, Hans Michael. Desenvolvimento sustentável: uma descrição das principais ferramentas de avaliação. Ambiente \& Sociedade, São Paulo, v. 7, n. 1, p.67-87, jan./jun. 2004.

VAZ, Caroline Rodrigues et al. Sistema de Gestão Ambiental em Instituições de Ensino Superior: uma revisão. GEPROS, Bauru, v. 5, n. 3, p.45-58, jul./set. 2010. 
Recebido: 27/12/2018

Aprovado: 22/04/2020

DOI: $10.3895 /$ rts.v16n42.9256

Como citar: VIEIRA, I.L.; SILVA.E.R. Revisão narrativa sobre práticas de gestão ambiental nas instituições públicas de ensino superior brasileiras. R. Tecnol. Soc., Curitiba, v. 16, n. 42, p. 75-93. jul/set. 2020. Disponível em: https://periodicos.utfpr.edu.br/rts/article/view/9256. Acesso em: XXX.

Correspondência:

Direito autoral: Este artigo está licenciado sob os termos da Licença Creative Commons-Atribuição 4.0 Internacional. 